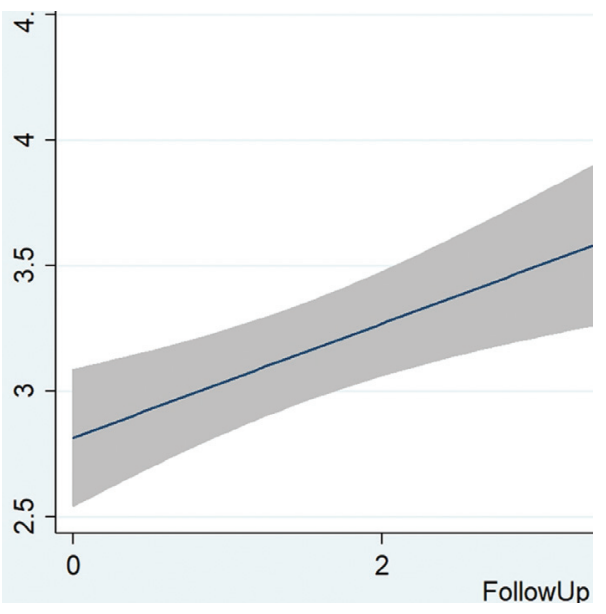

Conclusions: Work impairment is highly prevalent in contemporary rheumatoid arthritis patients. It is significantly correlated with mental health, even after adjusting for disease severity factors. Baseline mental health also predicts progression of work impairment. The relationship is likely bidirectional, and future research is justified to evaluate whether mental health interventions could improve work outcomes.

Disclosure of Interest: None declared DOI: 10.1136/annrheumdis-2018-eular.5395

\section{THU0101 TISSUE METABOLITE OF TYPE I COLLAGEN, C1M, AND CRP PREDICTS STRUCTURAL PROGRESSION OF RHEUMATOID ARTHRITIS}

A.C. Bay-Jensen ${ }^{1}$, A. Platt ${ }^{2}$, M. Jenkins ${ }^{3}$, M. Weinblatt ${ }^{4}$, I. Byrjalsen ${ }^{1}$, K. Musa ${ }^{1}$, M. C. Genovese ${ }^{5}$, M.A. Karsdall ${ }^{1}{ }^{1}$ Rheumatology, Nordic Bioscience Biomarkers and Research, Herlev, Denmark; ${ }^{2}$ Precision Medicine and Genomics; ${ }^{3}$ Global Medicines Development, AstraZeneca, Cambridge, UK; ${ }^{4}$ Division of Rheumatology, Brigham and Women's Hospital, Boston, MA; ${ }^{5}$ Division of Immunology and Rheumatology, Stanford University, Palo Alto, CA, USA

Background: Biomarkers of rheumatoid arthritis (RA) disease activity typically measure inflammation or autoimmunity (e.g. CRP, rheumatoid factor (RF)). Another class of biomarkers are structural proteins of the joint. C1M and C3M, metabolites of type I and III collagen, are such biomarkers. These biomarkers have previously been documented to provide additional value as compared to standard inflammation biomarkers, for prognosis and prediction of response to treatment ${ }^{1}$.

Objectives: We investigated the relationship of high serum levels of C1M or C3M to radiographic progression, and benchmarked to CRP levels and RF status, demonstrated to be associated with structural progression ${ }^{2}$.

Methods: Placebo treated patients of the OSK123 studies (Ph3 clinical trials testing efficacy of fostamatinib) with baseline serum biomarkers C1M, C3M, CRP and RF were included $\left(n_{B L}=474\right)$. Van der Heijde mTSS was calculated at baseline and 24 week $\left(\mathrm{n}_{24}=264\right)$. Progression was defined as moderate or rapid $(\geq 0.5$ or $\geq 5 \mathrm{mTSS}$ units/y). Patients were divided into subgroups; low, high or very high C1M, C3M and CRP (above/below median and highest quartile), or RF negative, positive and high positive $(\geq 110 \mathrm{U} / \mathrm{L})^{2}$. Difference in clinical parameters were analysed by Mann-Whitney/Chi-squared tests, and multivariate predictive calculations by Classification And Regression Tree analysis including covariates (age, $\mathrm{BMI}$, gender and disease activity assessment scores).

Results: High C1M, C3M and CRP levels were significantly associated with measures of disease activity $(p<0.05)$ and patient reported scores $(p<0.05)$. $R F_{\text {pos }}$ was also associated with disease active scores $(p<0.05)$. $R F_{\text {pos }}$ and $C R P$ $(p<0.001)$, as well as $C 1 M$ and C3M $(p<0.05)$, were significantly associated with mTSS at baseline. For prognostic measures, there were 2.5 and 4-fold as many rapid progressors in the $C 1 \mathrm{M}_{\text {high }}$ and $C R P_{\text {high }}(p<0.05)$, and in the $\mathrm{C}_{1} \mathrm{M}_{\text {veryhigh }}$ and $\mathrm{CRP}_{\text {veryhigh }}$ groups $(\mathrm{p}<0.001)$ compared $\mathrm{C}_{1} \mathrm{M}_{\text {low }}$ and $\mathrm{CRP}$ low, respectively. $\mathrm{C} 1 \mathrm{M}$ and CRP performed similarly in the predictive analysis with AUCs of 0.67 and 0.69 (table 1). The best model involving $\mathrm{C} 1 \mathrm{M}$ in predicting rapid progressor included BMI, SJC and HAQ (AUC 0.85), whereas the best model for CRP included CRP, BMI, SJC and HAQ (AUC 0.85). C3M and RF did not provide prognostic value.

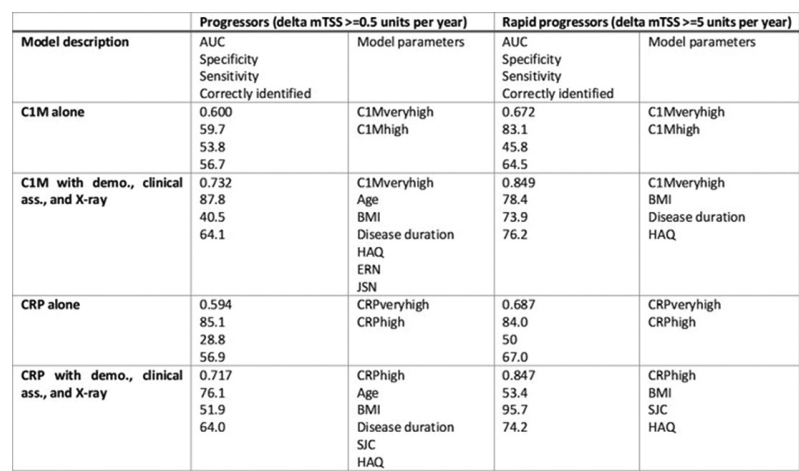

Conclusions: Of the four markers analysed only C1M and CRP were associated with structural progression. They seem to preform equally well, but reflect two different aspect of disease pathogenesis (tissue turnover vs. inflammation), thus may provide individual, but supplementary, information. These simple measures may be important for enrichment of clinical trials with structural progressors.

\section{REFERENCES:}

[1] Siebuhr A, et al. Serological identification of fast progressors of structural damage with rheumatoid arthritis. Arthritis Res. Ther 2013.

[2] Aletaha D, Alasti F, \& Smolen JS. Rheumatoid factor determines structural progression of rheumatoid arthritis dependent and independent of disease activity. Ann Rheum Dis 2013.

Disclosure of Interest: A. Bay-Jensen Shareholder of: Nordic Bioscience, Employee of: Nordic Bioscience, A. Platt Shareholder of: AstraZeneca, Employee of: AstraZeneca, M. Jenkins Employee of: AstraZeneca, M. Weinblatt: None declared, I. Byrjalsen Employee of: Nordic Bioscience, K. Musa Employee of: Nordic Bioscience, M. Genovese: None declared, M. Karsdal Shareholder of: Nordic Bioscience, Employee of: Nordic Bioscience DOI: 10.1136/annrheumdis-2018-eular.3028

\section{THU0102 HIGH RATES OF RESIDUAL DISEASE ACTIVITY DESPITE CURRENT THERAPIES IN A REAL LIFE RHEUMATOID ARTHRITISCOHORT: DATA FROM 1096 PATIENTS}

K. Thomas ${ }^{1}$, A. Lazarini ${ }^{1}$, E. Kaltsonoudis ${ }^{2}$, A. Drosos ${ }^{2}$, P. Tsatsani ${ }^{3}$, S. Gazi ${ }^{3}$, L. Pantazi ${ }^{4}$, K.A. Boki ${ }^{4}$, P. Katsimbri ${ }^{1}$, D. Boumpas ${ }^{1}$, K. Fragkiadaki ${ }^{1}$, M. Tektonidou ${ }^{1}$, P.P. Sfikakis ${ }^{1}$, K. Karagianni ${ }^{5}$, L. Sakkas ${ }^{5}$, E. Grika ${ }^{1}$, P. Vlachoyiannopoulos ${ }^{1}$, G. Evangelatos ${ }^{6}$, A. lliopoulos ${ }^{6}$, T. Dimitroulas $^{7}$ A. Garyfallos ${ }^{7}$, K. Melissaropoulos ${ }^{8}$, P. Georgiou ${ }^{8}$, M. Areti ${ }^{9}$, C. Georganas ${ }^{10}$ P. Vounotrypidis ${ }^{11}$, G. Kitas ${ }^{1}$, D. Vassilopoulos ${ }^{1}$, on behalf of Greek Rheumatology Society RA Study Group. ${ }^{1}$ Joint Rheumatology Program, National and Kapodistrian University of Athens School of Medicine, Athens; ${ }^{2}$ Rheumatology Clinic, University of loannina, loannina; ${ }^{3}$ Rheumatology Unit, KAT Hospital; ${ }^{4}$ Rheumatology Unit, Sismanoglio Hospital, Athens; ${ }^{5}$ Department of Rheumatology, University of Thessaly, Larissa; ${ }^{6}$ Rheumatology Unit, NIMTS Hospital, Athens; ${ }^{7}$ 4th Department of Medicine, Aristotle University, Thessaloniki; ${ }^{8}$ Rheumatology Unit, Agios Andreas Hospital, Patras; ${ }^{9}$ Private Practice, Livadeia; ${ }^{10}$ Private Practice, Athens; ${ }^{11}$ Private Practice, Thessaloniki, Greece

Background: It is unclear if the widespread use of biologic DMARDs (bDMARDs) and the implementation of the treat to target approach have led to better disease control in patients with rheumatoid arthritis (RA) in daily clinical practice.

Objectives: To study the longitudinal changes in disease activity in a large, real life, longitudinal RA cohort.

Methods: Multicenter (11 hospitals, 3 private offices), prospective, RA epidemiological study in Greece. Demographics, disease characteristics, treatments and co-morbidities were collected via a web-based platform in registered patients at baseline and one year after their 1st visit.

Results: 1.096 RA patients with available paired evaluations one year apart (mean interval: $13.4 \pm 3.6$ months) were included (women: $78 \%$, mean age: 62.8 years, mean disease duration: 11 years, RF and/or anti-CCP positive: 60\%, mean HAQ: $0.44 \pm 0.56)$. At baseline, $50 \%(n=548)$ of patients were on conventional DMARDs (csDMARDs) alone, $35 \%$ on cs- and b-DMARD combination $(n=379)$ and $11 \%$ on bDMARD monotherapy $(n=124)$. Among bDMARD treated patients, $60 \%$ were 